EESTI NSV TEADUSTE AKADEEMIA TOIMETISED. XIII KÖIDE

FCOSIKA-MATEMAATIKA- JA TEHNIKATEADUSTE SEERIA. 1964, NR. 4

ИЗВЕСТИЯ АКАДЕМИИ НАУК ЭСТОНСКОН ССР. ТОМ ХІІІ СЕРИЯ ФИЗИКО-МАТЕМАТИЧЕСКИХ И ТЕХНИЧЕСКИХ НАУК. 1964. № 4

\title{
ИЗУЧЕНИЕ СТРУКТУРЫ КЕТОНОВ МЕТОДОМ ГИДРИРОВАНИЯ И ГАЗОХРОМАТОГРАФИИ
}

\author{
И. КЛЕСМЕНТ, \\ кандидат технических наук
}

Продукты низкотемпературного разложения кислородсодержащих горючих ископаемых содержат много кислорода. Например, органическое вещество эстонского горючего сланца содержит $78,4 \div 78,8 \%$ С, $9,0 \div 9,9 \%$ Н и $11,3 \div 12,6 \%$ О, в результате этого свыше $50 \%$ молекул сланцевой полукоксовой смолы содержит кислород. Известно, что кислород сланцевой смолы находится в кислых (фенольных) и нейтральных, в основном в карбонильных функциональных группах $\left[{ }^{1,2}\right]$. Изучение их и́ндивидуального состава затруднено из-за присутствия большого количества изомеров.

Томпсон и др. $\left[{ }^{3,4}\right]$ показали, что кислород и серу возможно в молекулах заменить водородом, что значительно упрощает анализ. Гидрирование проводилось на катализаторе $0,5 \% \mathrm{Pd}$ на окиси алюминия в токе водорода при $175-250^{\circ} \mathrm{C}$. Вещество подавали в реактор со скоростью 1 мкл/мин. Қатализат конденсировали и его состав определяли газохроматографически. В основном по такому же методу проводилось iा дегидроксилирование фенолов [5]. Бероза [ $\left.{ }^{6}\right]$ переработал этот метод в обычный микрореакторный-газохроматографический метод: вещество (1-20 мкг) инжектировали в ток водорода, вместе с газом оно попадало в микрореактор и газохроматограф, снабженный пламенно-ионизационным детектором.

Целью настоящей работы было разработать такой же метод для анализа кетонов на обычном хроматографе, снабженном катарометром, определить оптимальные условия гидрирования кетонов в углеводороды и изучить влияние структуры кетонов на результаты катализа.

Применяемая методика и катализаторы описаны в предыдущих работах $[5,7]$. Использовали двухколоночный хроматограф УХ-1, первая колонка которого была заменена микрореактором гидрирования. Гидрируемое вещество вместе с газом-носителем - водородом - проходилю через реактор и хроматографическую колонку. Колонки имели длину 3-6 м, в качестве неподвижной фазы служили полиэтиленгликоль 4000 и дифенилформамид. Катализаторами служили платина и палладий в количестве $5 \%$ от носителя - диатомита. Объем катализатора в реакторе - 2 мл. Для получения сравнимых результатов скорость газа во всех опытах поддерживалась 60 мл/мин и объем пробы 4 мкл. Попытки использовать никель не дали положительных результатов из-за значительного разложения соединений.

Гидрированию подвергались следующие кетоны; ацетон, метилэтилкетон, $\boldsymbol{t}$-пентанон-3, 3-метил-бутанон-2, н-гексанон-3, н-гексанон-2,

3 ENSV TA Toimetised T-4. 64. 


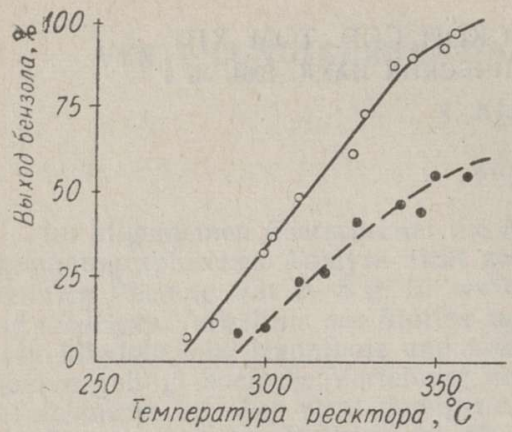

Рис. 1. Активности катализаторов по дегидрированию циклогексана в бензол. $a$ - активный Pd-катализатор, б - малоактивный $\mathrm{Pt}$-катализатор.

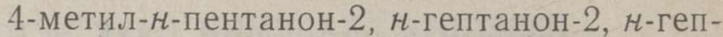
танон-4, 2.4-диметилпентанон-3, н-октанон-2, $\boldsymbol{H}$-нонанон-2, циклопентанон, циклогексанон, 2-метилциклогексанон, ацетофенон.

Опыты показали, что в отношении гидрирования карбонильной группы платиновые и палладиевые катализаторы равноценны. В работе применялись активные (свежеприготовленные и регенерированные) и малоактивные (частично отравленные при дегидроксилировании фенолов и дегидрировании нафтенов) катализаторы. Активность катализатора определялась по степени дегидрирования циклогексана в бензол.

Зависимость активности двух катализаторов от температуры приведена на рис. 1 .

Опыты показали, что результаты гидрирования кетонов зависели от активности катализаторов. В интервале от 200 дыо $350^{\circ}$ на активных катализаторах все вышеотмеченные кетоны гидрировались в углеводороды. При температурах до $250^{\circ}$ кетоны в некоторой степени адсорбировались на катализаторе, в результате чего времена их выхода увеличивались и форма пиков, соответствуюшая им на хроматограмме, была несимметричной. Выяснилось, что кетоны оказывают на катализатор отравляющее действие, его активность в отношении дегидрирования циклогексана падает. Особенно пассивирующими оказались циклические кетоны, - циклопентанон и циклогексанон. Однако кетоны гидрировались относительно легко, даже после многократного гидрирования на отравленном катализаторе в катализате кетонов не оставалось. Свойства катализатора легко восстанавливались продуванием воздуха при $300-350^{\circ}$ в течение 15 мин.

Малоактивные Pd- и Pt-катализаторы оказались более стабильными, в течение продолжительной работы их свойства не

Таблица :

Продукты гидрирования кетонов на малоактивном Pt-катализаторе

\begin{tabular}{|c|c|c|c|c|}
\hline \multirow[b]{2}{*}{$\begin{array}{c}\text { Название } \\
\text { кетонов }\end{array}$} & \multirow{2}{*}{ 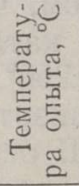 } & \multicolumn{3}{|c|}{ Выход продуктов, \% } \\
\hline & & $\begin{array}{l}\text { Углево- } \\
\text { дороды }\end{array}$ & $\mathrm{C}_{\text {пирты }}$ & $\begin{array}{l}\text { Heпро- } \\
\text { реагиро- } \\
\text { ванные } \\
\text { кетоны }\end{array}$ \\
\hline Ацетон & $\begin{array}{l}200 \\
250 \\
300 \\
350\end{array}$ & $\begin{array}{r}-* \\
2,8 \\
41,9 \\
98,0\end{array}$ & $\begin{array}{r}84,2 \\
46,8 \\
20,1 \\
2,0\end{array}$ & $\begin{array}{l}15,8 \\
50,4 \\
38,0 \\
-\end{array}$ \\
\hline H-Гексанон-3 & $\begin{array}{l}200 \\
250 \\
300 \\
350\end{array}$ & $\begin{array}{r}-* \\
68,1 \\
91,5 \\
100,0\end{array}$ & $\begin{array}{r}53,1 \\
6,5 \\
5,8 \\
-\end{array}$ & $\begin{array}{r}46,9 \\
25,4 \\
2,7 \\
-\end{array}$ \\
\hline н-Октанон-2 & $\begin{array}{l}200 \\
250 \\
300 \\
350\end{array}$ & $\begin{array}{r}{ }_{69}^{*}, 3 \\
94,5 \\
100,0\end{array}$ & $\begin{array}{l}66,6 \\
15,4 \\
- \\
-\end{array}$ & $\begin{array}{r}33,4 \\
15,3 \\
5,5 \\
-\end{array}$ \\
\hline Циклопентанон & $\left\{\begin{array}{l}200 \\
250 \\
300 \\
350\end{array}\right.$ & $\begin{array}{r}21,6 \\
31,6 \\
95,5 \\
100,0\end{array}$ & $\begin{array}{l}53,1 \\
45,1 \\
- \\
-\end{array}$ & $\begin{array}{r}25,3 \\
23,3 \\
4,5 \\
-\end{array}$ \\
\hline $\begin{array}{l}\text { 2-Метилцикло- } \\
\text { гексанон }\end{array}$ & $\left\{\begin{array}{l}200 \\
250 \\
300 \\
350\end{array}\right.$ & $\begin{array}{r}43,5 \\
59,0 \\
100,0 \\
100,0\end{array}$ & $\begin{array}{l}56,5 \\
41,0 \\
- \\
-\end{array}$ & - \\
\hline
\end{tabular}

* Оарразовалось немного углеводорода, но адсорбция на катализаторе препятствовала его изме рению. 
изменялись. При низких температурах кетоны на них полностью не гидрировались, часть их оставалась неизменной, часть восстанавливалась в спирты.

Образование спиртов из карбонильных соединений описано в монографии Әллиса $\left[{ }^{8}\right]$, реакция изучена также для использования продуктов оксосинтеза $[9,10]$.

Относительная стабильность малоактивного катализатора дала возможность изучить реакционную способность кетонов при разных температурах. Результаты гидрирования некоторых кетонов приведены в табл. 1. При температурах 300$350^{\circ}$ основные продукты гидрирования - углеводороды, при низких температурах - спирты. Скорость гидрирования последних низкая: углеводородов при $200-250^{\circ}$ образуется мало. Некоторое влияние имеют также молекулярный вес и структура молекулы. Высокомолекулярные и циклические кетоны гидрируются легче.

Особо низкими оказались скорости гидрирования первых гомологов кетонного ряда. На рис. 2 изображены результаты гидрирования ацетона, метил-этилкетона и циклопентанона при 250. Соотношение

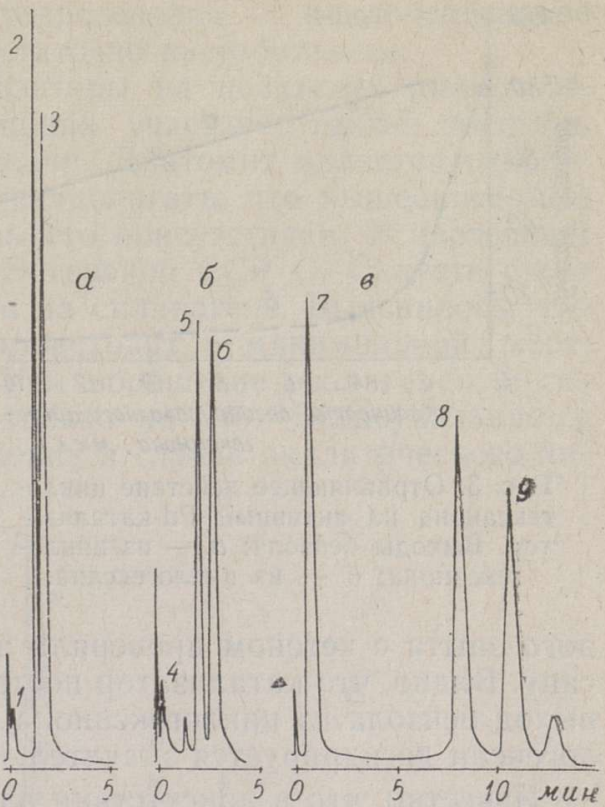

Рис. 2. Результаты гидрирования ацетона $(a)$, метил-этилкетона $(\sigma)$ и циклопіентанона (в) на малоактивном Pt-катализаторе при $250^{\circ} .1$ - пропан; 2 ацетон; 3 - пропанол-2, 4 - н-бутан; 5 - метил-этилкетон; 6 - бутанол- 2 ; 7 - циклопентан; 8 -циклопентанон; 9 - циклопентанол. Условия хроматографирования: СЖФ - полиэтиленгликоль $4000,20 \%$ от веса диатомита, длина колонки $3,2 \mu, t=150^{\circ}$, расход водорода $60 \mathrm{~m} /$ мин, давление 1,7 атм. продуктов их ғидрирования - пропан: бутан : циклопентан равно $1: 1,6: 10$. Такой результат невозможни обосновать только различием молекулярного веса, очевидно скорость. гидрирования ацетона и метилэтилкетона уменьшают другие факторы:

Таблица 2

Выход ароматических углеводородов из циклических кетонов и соответствующих углеводородов на малоактивном Pt-катализаторе

\begin{tabular}{|c|c|c|c|}
\hline \multirow{2}{*}{$\begin{array}{c}\text { Название кетона } 1: \\
\text { соответствуюшего } \\
\text { углеводорода }\end{array}$} & \multirow{2}{*}{$\begin{array}{l}\text { Темпе- } \\
\text { ратура } \\
\text { ката- } \\
\text { лиза, }{ }^{\circ} \mathrm{C}\end{array}$} & \multicolumn{2}{|c|}{$\begin{array}{c}\text { Выход ароматических } \\
\text { углеводородов }\end{array}$} \\
\hline & & из кетона & $\begin{array}{c}\text { из углево- } \\
\text { дорода }\end{array}$ \\
\hline $\begin{array}{c}\text { Циклогексанон, } \\
\text { циклогексан }\end{array}$ & $\begin{array}{l}250 \\
300 \\
350\end{array}$ & $\begin{array}{r}2,0 \\
12,8 \\
57,1\end{array}$ & $\begin{array}{r}- \\
3,0 \\
44,2\end{array}$ \\
\hline $\begin{array}{l}\text { Метилциклогекса- } \\
\text { нон, } \\
\text { метилциклогек- } \\
\text { сан }\end{array}$ & $\left\{\begin{array}{l}250 \\
300 \\
350\end{array}\right.$ & $\begin{array}{r}5,7 \\
16,0 \\
81,4\end{array}$ & $\begin{array}{l}\overline{11,0} \\
71,9\end{array}$ \\
\hline $\begin{array}{l}\text { Ацетофенон, } \\
\text { этилбензол }\end{array}$ & $\left\{\begin{array}{l}250 \\
300 \\
350\end{array}\right.$ & $\begin{array}{r}79,6 \\
93,6 \\
100,0\end{array}$ & $\begin{array}{r}82,2 \\
95,6 \\
100,0\end{array}$ \\
\hline
\end{tabular}

структурного характеpa.

На Pd- и Pt-катализаторах протекает также гидрирование ароматических соединений й дегидрирование нафтенов с шестичленным кольцом. Опыты показали, что присутствие карбонильной группы в молекуле оказывает заметное влияние на скорость реакции. В табл. 2 приведены выходы ароматических углеводородов: из циклогексанона, метилциклогексанона: ш 


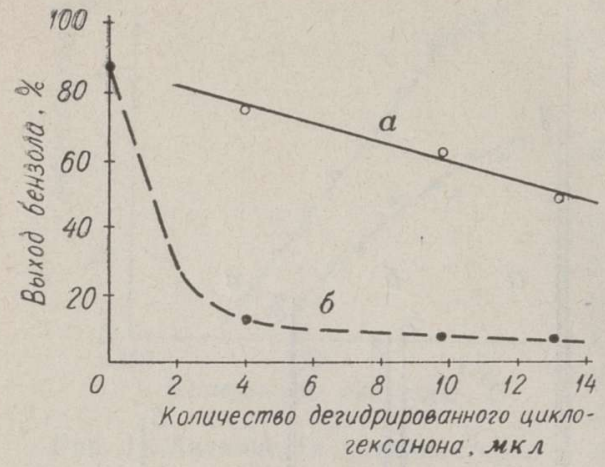

Тис. 3. Отравляющее действие циклотексанона на активный Pd-катализатор. Выходы бензола: $a$ - из циклогексанона; 6 - из циклогексана. ацетофенона, а также из соответствующих углеводородов. При всех температурах катализа циклогексаноны ароматизируются больше, чем соответствующие нафтены. Результаты гидрирования ацетофенона и этилбензола близки, можно предположить, что присутствие карбонильной группы в боковой цепи не оказывает существенного влияния на скорость реакции в цикле.

Опыты проводились на малоактивном, но стабильном катализаторе. На рис. 3 показаны результаты многократного последовательного катализа циклогексанона при $335^{\circ}$ на активном катализаторе. После каж-

дото опыта с кетоном проверяли активность катализатора по циклогексану. Видно, что катализатор постепенно отравляется, с каждым опытом выход бензола из циклогексанона уменьшается. В тех же условиях циклогексан дегидрируется значительно меньше, чем циклогексанон.

Известно, что в присутствии алкильных цепей скорость дегидрогенизации нафтенов увеличивается [7]. Такое же влияние карбонильной труппы на скорость реакции обуслсвливается вероятно другими факторами. Реакция карбонильной группы с водородом необратима и происходит скорее, чем дегидрирование цикла. Можно предположить, что при высоких температурах после разрыва связи С-O без промежутсч- ного насыщения сразу образуется ароматическая связь С-С. Отсутствие промежуточной реакции гидрирования может облегчить дегидрирование циклогексанонов.

При высоких температурах на катализаторе кроме реакций присоединения и отщепления водорода происходят нежелательные реакции гидрокрекинга. Особенно легко разлагаются высокоразветвленные соединения, подвергаются гидрогенолизу также производные циклопентана (их кольцо размыкается [7]).

Томпсон и другие $\left[{ }^{4}\right]$ установили, что кислородсодержащая функциональная группа ослабляет связь в цепи углеводорода между двумя углеродными атомами, из которых один атом углерода связан с кислородом, а у другого цепь углеводорода разветвляется. По его данным такие соединения разлагались уже при температурах ниже $200^{\circ}$. В наших опытах скелеты всех кетонов оказались стойкими на катализаторе до $300^{\circ}$. При более высоких температурах указанные соединения частично разлагались. В таб́л. 3 показаны результаты катализа двух кетонов и соответствующих углеводородов

Таблица 3

Конверсия кетонов и углеводородов на активном Pd-диатомит катализаторе

\begin{tabular}{l|r|r|r}
\hline \multirow{2}{*}{ Название соединений } & \multicolumn{2}{|c}{ Разлагался } \\
& при температуре, \\
\cline { 2 - 4 } & 300 & 325 & 350 \\
\hline & & & \\
$2,4-$ Диметилпента- & 8 & 29 & 60 \\
нон-3 & 6 & 7 & 35 \\
$2,4-$ Диметилпентан & 18 & 40 & 74 \\
Циклопентанон & 24 & 36 & 49 \\
Метилциклопентан &
\end{tabular}
на $\mathrm{Pd}$-диатомит катализаторе. Опыт с 2,4-диметил-пентаноном-3 показал, что действительно разветвленные кетоны оказались менее стабилььжыми, чем соответствующие углеводороды. Сравнение результатов гидрирования производных циклопентана не позволяет точно установить 
влияние карбонильной группы на гидрогенолиз - циклопентановое кольцо является уже само по себе достаточно нестабильным.

Установлено, что Pt- и Pd-катализаторы на носителях имеют бифункциональный характер [11], в реакциях участвует также носитель металла, способствуя реакции деструкции. Диатомит является относительно инертным [7], однако можно предполагать, что вышеописанные реакции отщепления были обусловлены его присутствием. В настоящей работе совместно с аспиранткой АН Эстонской ССР С. Салусте были: изучены свойства катализатора $5 \%$ Pd на силикагеле. Выяснилось, что на этом катализаторе деструкция происходит в минимальной мере. Даже при $350^{\circ}$ 2,4-диметилпентан на нем вообще не разлагался, а соответствующий кетон расшеплялся только на $2 \%$. Вышеуказанному катализатору следует отдать предпочтение в случае аналитического характера работы. В целях установления разветвленности структуры кетонов можно использовать катализатор на диатомите.

Опыты на малоактивном катализаторе дали некоторые объяснения о химизме и кинетике гидрирования кетонов. Однако в аналитической работе неполное гидрирование и образование спиртов вызывает дополнительные труднссти, следовательно необходимо использовать активный катализатор. Чтобы сохранить активность катализатора, необходимо регенерировать его через каждые 3-4 анализа.

Существенное влияние на результаты гидрирования оказывает температура катализа. Ниже $250^{\circ}$, особенно при примене-

Рис. 4. Гидрогенизационный анализ искусственной смеси кетонов. Гидрирование при $325^{\circ}, 2$ мл катализатора $5 \% \mathrm{Pd}$ на силикагеле. $a$ - хроматограмма исходной смеси кетонов; $\sigma$ и 8 - хроматограммы катализата. 1 н-пентанон; 2 - 2,4-диметилпентанон-3; 3 - $н$-гептанон- $3 ; 4$ - циклопентанон; 5 - н-октанон- $2 ; 6$ - цнилогексанон; 7 - $H$-нонанон- $2 ; 8$ н-пентан; 9 - 2,4-диметилпентан; 10 - циклопентан; 11 - н-гептан; 12 - н-октан; 13 - бензол; 14 $н$-нонан. Условия хроматографирования: $a$ и б - СЖФ - полиэтиленгликоль $4000,20 \%$ от веса диатомита, длина колонки $6 \mu, t=180^{\circ}$, расход водорода 60 мл/мин, давление 2,0 ат $і$; в- СЖФ - дифенилформамид, $20 \%$ от веса диатомита, длина колонки $6 \mu, t=100^{\circ}$, расход водорода $60 \mathrm{мл/мин,} \mathrm{давленне} \mathrm{1,2} \mathrm{атм.}$

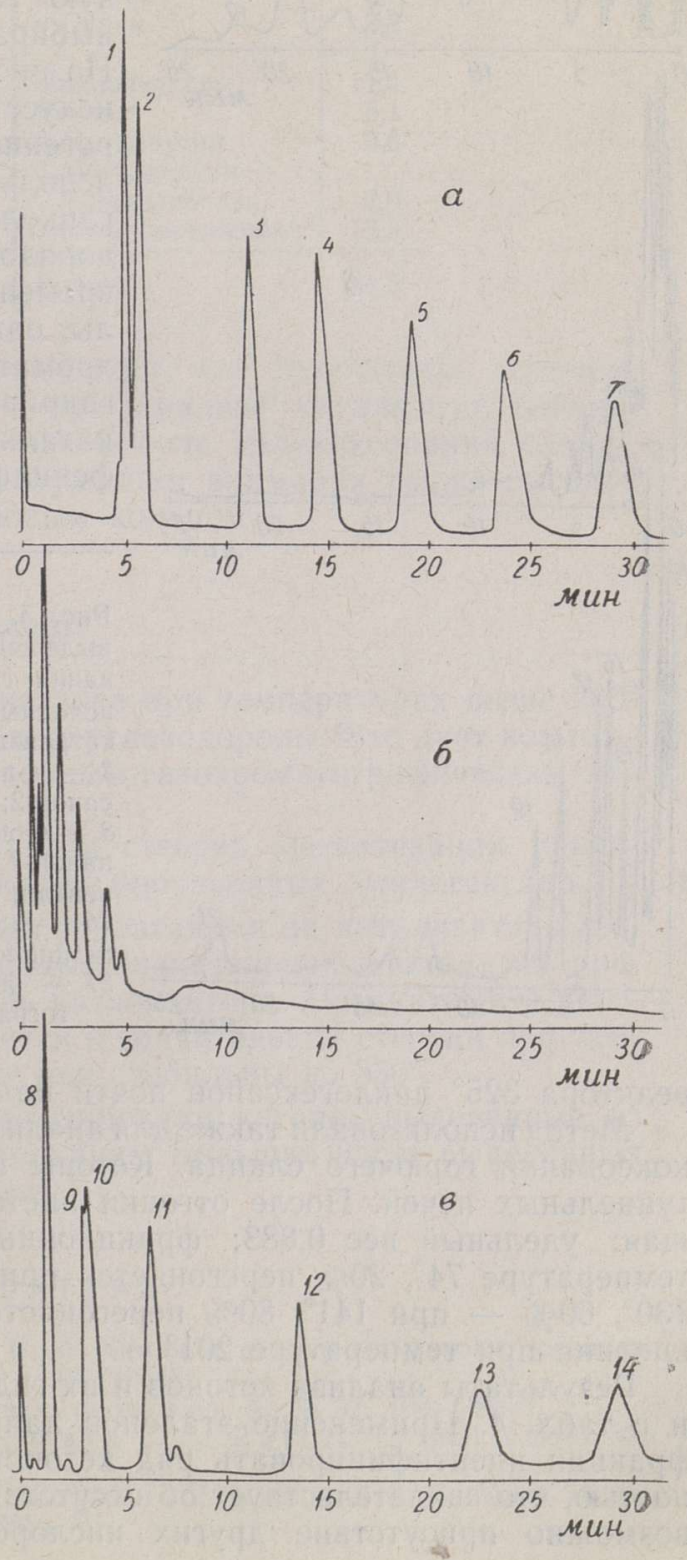




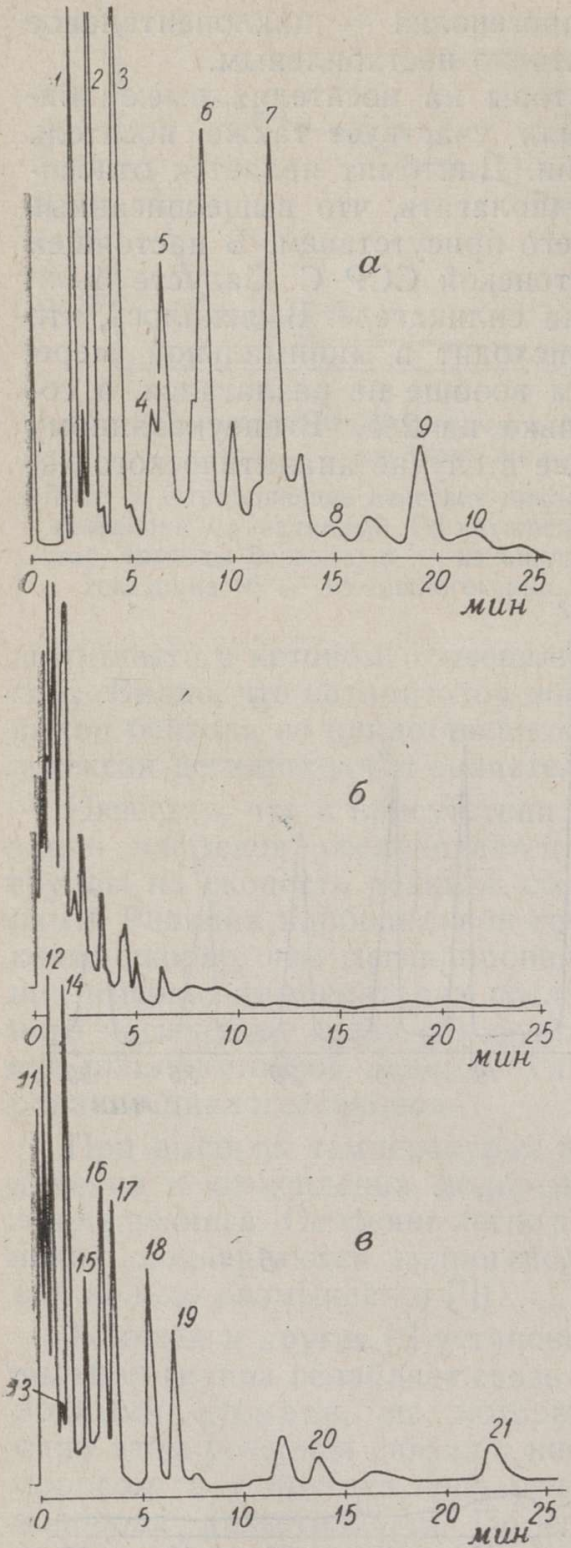

нии силикагеля в качестве носителя, кетоны адсорбируются на катализаторе. По степени адсорбируемости можно судить о характере гидрируемых соединений [ $\left.{ }^{6}\right]$, но адсорбция понижает точность анализа. В пределах 270-290 скорость дегидрогенизации нафтенов и гидрирования ароматических колец низка, они сохраняют в основном свой исходный характер. Выше $325^{\circ}$ циклогексаноны количественно ароматизируются, эту реакцию можно использовать для их идентификации. Оптимальную температуру гидрирования надо выбирать исходя из этих соображений. На рис. 4 изображены хроматограммы искусственной смеси кетонов и его гидрогенизатов. Для разделения кетонов использовалась колонка с полиэтиленгликолем. Для идентификации углеводородов эта же колонка непригодна времена удерживания их слишком малы, однако отсутствие пиков кетонов на хроматограмме указывает на полное гидрирование последних. Для анализа катализата использовали кольнку с дифенилформамидом. При температуре

Рис. 5. Гидрогенизационный анализ кетонов, выделенных из подсмольной воды полукоксования горючего сланца: $a$ - хроматограмма исходных кетонов; $\sigma$ и $в-$ хроматограммы катализата. 1 - ацетон; 2 - метил-этилкетон; 3 - $н$-пентанон; $4-\mu$-гексанон- $3 ; 5-\mu$-гексанон- $2 ; 6-н$-гептанон-3; 7 - циклопентанон; 8 - -октанон- $2 ; 9$ - циклогексанон; $10-\mathrm{H}$-нонанон-2; 11 - пропан; 12 - бутан; 13 - изопентан; 14 - н-пентан; 15 - 2-метил-пентан; 16 - н-гексан; 17 - циклопентан; 18 - метилциклопентан; 19 - $н$-гептан; 20 - н-октан; 21 - бензол. Условия гидрирования и хроматографирования такие же как на рис. 4.

реактора $325^{\circ}$ циклогексанон почти полностью превращался в бензол.

Метод использовали также для анализа кетонов, получаемых при полукоксовании горючего сланца. Кетоны выделяли из подсмольной воды туннельных печей. После отгонки ацетона их характеристика следующая: удельный вес 0,883; фракционный состав: начало кипения при температуре $74^{\circ}, 20 \%$ перегоняется при температуре $104^{\circ}, 40 \%$ - при $130^{\circ}, 60 \%$ - при $141^{\circ}, 80 \%$ перегоняется при температуре $165^{\circ}$, конел кипения при температуре $201^{\circ}$.

Результаты анализа кетонов и их гидрогенизата приведены на рис. 5 и в табл. 4. Применение эталонов дало возможность уже в исходной фракции идентифицировать ряд кетонсв. Фракция гидрировалась полностью, что свидетельствует об отсутствии в ней углеводородов. Однако возможно присутствие других кислородных соединений, кроме кето- 
Таблициа 4

Состав тяжелой фракции кетонов, выделенных из подсмольной воды полукоксования горючего сланца

\begin{tabular}{|c|c|c|c|}
\hline \multicolumn{2}{|c|}{ Состав кетонов } & \multicolumn{2}{|c|}{$\begin{array}{c}\text { Состав гидрогенизата } \\
\text { кетонов }\end{array}$} \\
\hline $\begin{array}{c}\text { Название } \\
\text { кетона }\end{array}$ & $\%$ & $\begin{array}{c}\text { Название } \\
\text { углеводорода }\end{array}$ & $\%$ \\
\hline $\begin{array}{l}\text { Ацетон } \\
\text { Метил-этилкетон } \\
\text { н-Пентанон-3 } \\
\text { н-Гексанон-3 } \\
\text { н-Гексанон-2 } \\
\text { н-Гептанон-3 } \\
\text { н-Октанон-2 } \\
\text { н-Нонанон-2 } \\
\text { Циклопентанон } \\
\text { Циклогексанон }\end{array}$ & $\begin{array}{r}10,8 \\
12,5 \\
14,0 \\
3,3 \\
6,2 \\
10,5 \\
0,8 \\
0,8 \\
15,8 \\
5,2\end{array}$ & $\begin{array}{l}\text { Пропан } \\
\text {-Бутан } \\
\text { н-Пентан } \\
\text { H-Гексан } \\
\text { H-Гептан } \\
\text { H-Октан } \\
\text { Циклопентан } \\
\text { Бензол } \\
\text { 2-Метилбутан } \\
\text { 2-Метилпентан + } \\
\text { 3-метилпентан } \\
\text { Метилциклопентан }\end{array}$ & $\begin{array}{r}11,0 \\
11,5 \\
14,5 \\
10,5 \\
8,7 \\
2,2 \\
11,4 \\
5,1 \\
0,6 \\
7,0 \\
12,3\end{array}$ \\
\hline Всего & 79,9 & Bcero & 84,8 \\
\hline
\end{tabular}

нов. Сравнение данных табл. 4 показывает, что результаты, полученные при прямом анализе кетонов и при анализе катализата, близки.

Алифатические кетоны в подсмольной воде полукоксования сланца в основном имеют прямую цепь. Заслуживает внимания также высокое содержание кетонов с циклопентановым кольцом.

\section{Выводы}

1. На активном Pd- и $\mathrm{Pt}$-катализаторе при температурах выше $200^{\circ}$ кетоны гидрируются в соответствующие углеводороды. Это дает возможность анализировать их микрореакторным-газохроматографическим методом.

2. В одинаковых условиях катализа степень ароматизации циклогексанонов выше, чем соответствующих производных циклогексана.

3. Кетоны с разветвленной цепью разлагаются на катализаторе легче, чем соответствующие углеводороды. Значительное влияние на процесс разложения оказывает носитель катализатора. На диатомите кетоны с разветвленной цепью разлагаются в значительной степени при темпіературах выше $300^{\circ}$, на силикагеле они стабильны до $350^{\circ}$.

4. Разработанным методом анализировали кетоны, выделенные из подсмольной воды полукоксования сланцев. Большая часть выделенных кетоноов имела прямолинейную структуру.

\section{ЛИТЕРАТ У РА}

1. Семен"ов С. С., Г.уревч Б. Е., В сб. Химия и технология горючих сланцев и продуктов их переработки, вып. 2, 49 (1954).

2. Палу оя В. Т., Тр. Таллинск. политехн. нн-та, Сер. А, № 97, 104 (1957).

3. Thomps on C. J., Colem a n H. J., W a rd C. C., R a 11 H. T., Anal. Chem., 32, No. 3,424 (1960).

4. Thompson C. J., Colem a n H. J., Hopkins R. L., Ward C. C., Ra 11 H. T., Anal. Chem., 32, No. 12, 1762 (1960). 
5. Клесмент И. Р., Э й зен О. Г., Горючие сланцы, бюллетень Государственного Комитета Совета Министров Эст. ССР по координации научно-исслед. работ. № 5, 30 (1963).

6. B e r o z a M., Anal. Chem., 34, No. 13, 1801 (1962).

7. Клесмент И. Р., Р анг С. А.,. Э̆ й зен О. Г., Нефтехимия, № 6, 867 (1963).

8. E 11 is C., Hydrogenation of organic substances. Routledge Ltd., London, 1931.

9. Л евин С. З., Карпов А. З., Дине р И. С., Грибова И. Г., Химия и технология топлива, № 5, 51 (1958).

10. Башки ро в А. Н., Химия и технология топлива, № 7,39 (1958).

11. Keulemans A. J. M., S chuit G. C. A., In collection: The mechanism of heterogenous catalysis. Ed. by J. H. de Boer, Elsevier PC, Amsterdam, 1960, 159.

Ніститут химии

Академии наук Эстонской ССР
Поступила в редакцию

3. III 1964

\title{
KETOONIDE STRUKTUURI MÄÄRAMINE HÜDROGEENIMISE JA GAASIKROMATOGRAAFIA ABIL
}

\author{
I. Klesment, \\ tehnikateaduste kandidaat
}

\section{Resümee}

Töötati välja mikroreaktor-gaasikromatograafiline meetod karbonüülühendite hüdrogeenimiseks süsivesinikeks ja katalüsaadi analüüsiks. Uuriti hüdrogeenimistemperatuuri mõju produktide saagisele ja destruktiivsete protsesside sõltuvust ketoonide struktuurist.

Väljatöötatud meetodiga määrati pōlevkivi utteveest eraldatud ketoonide koosseis.

Eesti NSV Teaduste Akadeemia

Keemia Instituut
Saaibus toimetusse

3. III 1964

\section{DIE. BESTIMMUNG DER STRUKTUR DER KETONE DURCH HYDRIERUNG UND GASCHROMATOGRAPHIE}

\author{
I. Klesment \\ Zusammenfassung
}

Es wurde eine mikroreaktor-gaschromatographische Methode für die Hydrierung der Karbonylverbindungen in Kohlenwasserstoffen und für die Analyse des Katalysats ausgearbeitet.

Der Einfluss der Hydrierungstemperatur auf die. Ausbeute der Produkte und der Einfluss der Struktur der Ketone auf die destruktiven Prozesse wurden untersucht.

Auf Grund der ausgearbeiteten Methode wurde die Zusammensetzung der Ketone bestimmt, die aus dem Schwelwasser des Schieferteers entfernt wurden.

Institut für Chemie

der Akademie der Wissenschaften der Estnischen SSR
Eingegangen am 3. März 1964 